\section{Organ Retrieval Surgery: Management of Left-sided Inferior Vena Cava}

Sir,

The true anatomical variations resulting from congenital anomalies of inferior vena cava (IVC) are rare. They are identified on abdominal cross-sectional imaging, post-mortem examination, and during cadaveric dissection. The reported incidence is between 0.2 to $3 \%{ }^{1,2}$ Clinically, the left-sided IVC has no bearing on the health of the individual. However, during the living and deceased kidney donation, this variation affects the operative planning. Left-sided IVC leads to smaller length of the left renal vein and can also be associated with renal artery variations and presence of accessory renal arteries. Hence, in living kidney donations, appropriate preoperative planning is considered or kidney donation from the donor with IVC anomalies is cancelled. ${ }^{3}$ However, in deceased donation, this issue is only identified at the time of donor surgery, since large percentage of deceased donation cases do not proceed for cross-sectional imaging of abdomen.

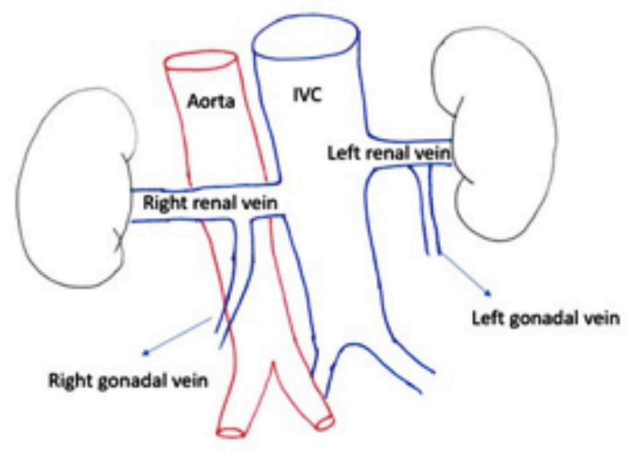

Figure 1: The distribution of aorta, left-sided inferior vena cava (IVC), right and left renal veins.

We present a case of a 49-year patient declared brain-dead, following road traffic incident. The organ procurement procedure was initiated and surgery was performed. Standard retroperitoneal dissection was performed. No IVC was identified on the right side. Further dissection identified left-sided IVC (Figures 1 and 2). Both right and left renal veins were identified. Left-sided renal vein was short. The right-sided renal vein was long and crossed aorta anteriorly. The junction of the common iliac veins to form IVC was lateral and to the left of the aortic bifurcation. The ureters were identified bilaterally to prevent inadvertent injury. At the time of cross-clamping, the venting of the perfusate was performed in the right atrium to preserve full length of the IVC. During the cold phase, the right renal vein was divided close to the IVC and the full length of IVC was preserved with the left renal vein.

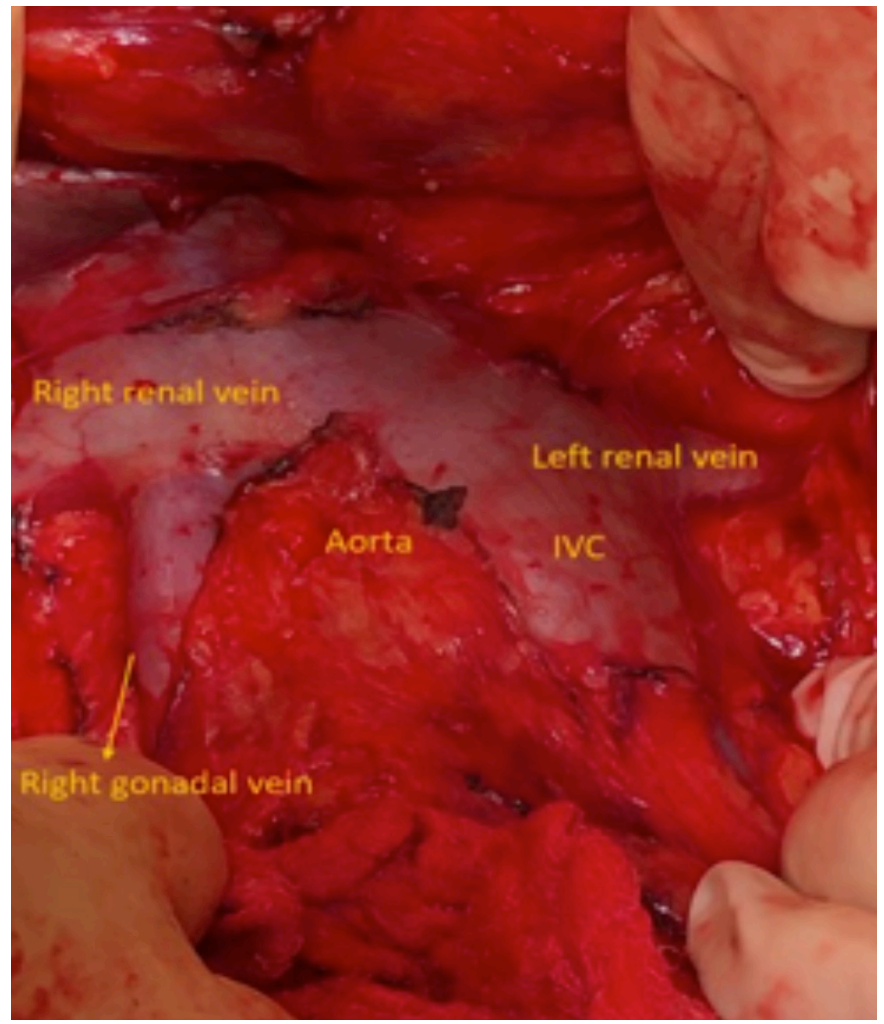

Figure 2: Anomalies of left-sided inferior vena cava (IVC) and presence of large right-sided gonadal vein.

The congenital anomalies of IVC result from defects of abnormal fusion and regression during sixth to $10^{\text {th }}$ week of gestation. ${ }^{4}$ These anomalies lead to subsequent anatomical variations of the IVC, which include duplicate IVC, left-sided IVC, circum-aortic renal vein, retro-aortic IVC and anomalous periureteral bands.

In living, related left kidney donation is excluded because of shorth length of renal vein. In deceased donation, this will be guided by the centre accepting the organ and an alternate strategy of leaving the IVC with the left-sided renal vein and dividing the right renal vein close to the site of origin of IVC.

\section{CONFLICT OF INTEREST:}

Authors do not report conflict of interest.

\section{AUTHORS' CONTRIBUTION:}

GMD: Contributed in drafting the article.

SA: Collecting references, reviewed current literature and updated review.

AM: Corresponding author, responsible for accuracy of information being published.

\section{REFERENCES}

1. Aljabri B, MacDonald PS, Satin R, Stein LS, Obrand DI, Steinmetz OK. Incidence of major venous and renal anomalies relevant to aortoiliac surgery as demonstrated by computed tomography. Ann Vasc Surg 2001; 15(6): 615-8. doi: 10.1007/s10016-001-0095-7.

2. Forster J, Biyani CS, Weston PM. A gentle reminder in the 
laparoscopic era left-sided inferior vena cava. Int Urol Nephrol 2006; 38(3-4):439-42. doi: 10.1007/s11255005-4028-1.

3. Kim MH, Jun KW, Moon IS, Kim Jl. Clinical importance of congenital anomalies of the inferior vena cava in organ procurement surgery from a deceased donor: Two case reports. Ann Surg Treat Res 2016; 91(5):260-4. doi: 10.4174/astr.2016.91.5.260.

4. Giordano JM, Trout $\mathrm{HH}$, 3rd. Anomalies of the inferior vena cava. J Vasc Surg 1986; 3(6):924-8. doi: 10.1067/ mva.1986.avs0030924.
Ghulam Murtaza Dar', Shahzad Ahmed ${ }^{1}$ and Ahmad Mirza ${ }^{2}$

${ }^{1}$ Royal Oldham Hospital, Oldham, UK

${ }^{2}$ Manchester Royal Infirmary, Manchester, UK

Correspondence to: Dr. Ahmad Mirza, Manchester Royal Infirmary, Manchester, UK

E-mail: akmirza2000@yahoo.com

Received: December 31, 2019; Revised: January 25, 2020; Accepted: February 10, 2020

DOI: https://doi.org/10.29271/jcpsp.2020.12.1358 